\title{
The marginal fit of lithium disilicate crowns: Press vs. CAD/CAM
}

\section{Basel AZAR(a) \\ Steve ECKERT ${ }^{(b)}$ \\ Josef KUNKELA ${ }^{(c)}$ \\ Tomaš INGR ${ }^{(d)}$ \\ Radek MOUNAJJED ${ }^{(a)}$}

(a)Palacky University, Institute of Dentistry and Oral Sciences, Olomouc, Czech Republic.

(b)Mayo Clinic, College of Medicine,

Rochester, MN, USA

(c) Private Clinic, Jindřichův Hradec, Czech Republic.

(d) Palacky University, Faculty of Science, Department of Experimental Physics, Olomouc, Czech Republic.
Declaration of Interest: The authors certify that they have no commercial or associative interest that represents a conflict of interest in connection with the manuscript.

\section{Corresponding author:}

Basel Azar

E-mail: baselazar1@hotmail.com

hitps://doi.org/10.1590/1807-3107/2018.vol32.0001

Submitted: Apr 27, 2017

Accepted for publication: Nov 13, 2017

Last revision: Nov 28, 2017
Abstract: This study aimed to compare the vertical marginal gap of teeth restored with lithium disilicate crowns fabricated using CAD/CAM or by pressed ceramic approach. Twenty mandibular third molar teeth were collected after surgical extractions and prepared to receive full veneer crowns. Teeth were optically scanned and lithium disilicate blocks were used to fabricate crowns using CAD/CAM technique. Polyvinyl siloxane impressions of the prepared teeth were made and monolithic pressed lithium disilicate crowns were fabricated. The marginal gap was measured using optical microscope at 200× magnification (Keyence VHX-5000, Japan). Statistical analysis was performed using Wilcoxon test. The lithium disilicate pressed crowns had significantly smaller $(p=0.006)$ marginal gaps $(38 \pm 12 \mu \mathrm{m})$ than the lithium disilicate CAD/CAM crowns $(45 \pm 12 \mu \mathrm{m})$. This research indicates that lithium disilicate crowns fabricated with the press technique have measurably smaller marginal gaps compared with those fabricated with CAD/CAM technique within in vitro environments. The marginal gaps achieved by the crowns across all groups were within a clinically acceptable range.

Keywords: Crowns; Marginal Fit, Press, CAD/CAM, Lithium Disilicate

\section{Introduction}

Lithium disilicate is a ceramic material that is recommended for the fabrication of dental restorations including single crowns and short span fixed dental prostheses. The material is available in pre-sintered blocks for chairside milling using CAD/CAM systems. ${ }^{1}$ With this method, clinicians can fabricate restorations during a single visit by using intraoral digital impressions and in-office milling. ${ }^{2}$ Following the initial stages of fabrication, crowns must be heat-treated to allow the crystallization process to take place and to achieve maximum strength. ${ }^{3,4}$ Lithium disilicate restorations can also be fabricated using the lost-wax, pressed ceramic technique. Ingots of lithium disilicate are heat-pressed into a mold within the ceramic furnace to obtain the desired shape after the wax burn-out. ${ }^{5,6}$ Regarding the strength of the material, pressed lithium disilicate is $11 \%$ stronger than the CAD/CAM lithium disilicate according to Ivoclar's 2011scientific report.

The recent FDI document on oral health states that modern dentistry should provide oral care that allow patients to achieve an improved oral health status. ${ }^{7}$ One factor that should be considered is the fit of the prosthesis to the tooth. ${ }^{8}$ 
The terminal portion of the prepared tooth is termed the finish line. ${ }^{9}$ The marginal gap is the perpendicular distance from the internal surface of the restoration to the finish line of the preparation. ${ }^{10}$ Classic descriptions of acceptable marginal gaps have generally been based upon the anticipated technical limits associated with the making of a new restoration. Technical limits however may not allow the achievement of the goals associated with a new restoration. A gap between the margin of the restoration and the finish line of the tooth preparation should, in theory, be small enough to prevent ingress of saliva and/or lactic acid, which is the byproduct of bacterial metabolism. ${ }^{11}$ Obviously, such a gap would be measured at the molecular level. However, most definitions of "closed margins" describe gaps of 100 $\mu \mathrm{m}$ or greater. ${ }^{12,13}$ Considering that Streptococcus mutans is a bacteria of approximately $0.75 \mu \mathrm{m}$ in diameter, ${ }^{14}$ such a marginal discrepancy would not only fail in the molecular level but it would not even preclude ingress of bacteria. These observations highlight the difference between idealized theoretical marginal discrepancy and clinical reality.

Marginal fit is one of the basic factors in the success of restorations. ${ }^{15,16}$ Poor marginal fit might lead to cement dissolution, marginal discoloration or staining, microleakage, and secondary caries. ${ }^{17}$ Therefore, it is important to minimize marginal gaps to decrease the incidence of associated complications. Moreover, it is not clear if the restorations fabricated by the CAD-CAM systems show comparable adaptation level to the restorations fabricated by the dental laboratory technician, as the literature is usually limited to the comparison between different CAD-CAM systems ${ }^{3,18-22}$ and only few studies have a control group. ${ }^{23,24}$ Therefore, the aim of this study was to compare the marginal opening of pressed lithium disilicate crowns with those using CAD/CAM techniques. The null hypothesis was that there is no statistically significant difference between the marginal gaps of the 2 techniques (press and CAD/CAM).

\section{Methods}

This study has been conducted in full accordance with the World Medical Association Declaration of Helsinki. The study has been independently reviewed and approved by an ethics committee at Palacky
University. A verbal consent - approved by the ethics committee - was obtained from the teeth donors involved in the study. Twenty extracted mandibular third molars were collected at the department of oral surgery, Palacky University. Following disinfection with $10 \%$ formalin solution for 7 days (Histofor, Pro-charitu, Czech Republic), teeth were inserted in acrylic bases (Dentalon, Heraeus Kulzer GmbH, Germany). As an attempt to standardize teeth preparations, teeth were prepared by only one author under $4 \times$ magnification (Univet, Italy) to receive lithium disilicate ceramic crowns (IPS e.max, Ivoclar Vivadent, Liechtenstein) following the protocol: chamfer finishing line of $1 \mathrm{~mm}$, occlusal reduction of $2 \mathrm{~mm}$, and axial reduction of 1.5 $\mathrm{mm}$ (Figure 1). Teeth were digitally scanned using (CEREC Omnicam, Sirona, Germany). Crowns were designed on the software CEREC SW 4.4 (Sirona, Germany), before milling crowns from blocks (IPS e.max CAD, Ivoclar Vivadent, Liechtenstein) in a milling machine (CEREC MC XL, Sirona) and fully crystallizing the crown in a special furnace (Programat CS2, Ivoclar Vivadent, Liechtenstein).

Traditional dental impressions of the prepared teeth were made using polyvinyl siloxane (Express XT, 3M ESPE, USA). Type IV Stone models (Shera premium type IV, SHERA, Germany) were then fabricated. Wax patterns (Geo classic opak, Renfert, Germany) for crowns were created by one technician. The wax patterns were invested in flasks using investment material (Pressvest speed, Ivoclar Vivadent, Liechtenstein), before burning the wax out in a furnace. Lithium disilicate press ingots (IPS e.max press, Ivoclar Vivadent, Liechtenstein) were heat-pressed. As a result, 20 pressed crowns and 20 CAD/CAM crowns were fabricated.

Measurement of the marginal gap was done at the Faculty of Science - Palacky University using optical microscope at $200 \times$ magnification and a special image analyzing software attached to the microscope (Keyence VHX-5000, Japan). The measurements were performed on 25 points on the finishing line of each tooth (Figure 2). Statistical analysis was performed using Wilcoxon test to compare the differences between the marginal gaps of e.max press and e.max CAD crowns. In addition, Kruskal-Wallis test was used to compare the differences between values measured on different teeth for each technique. 


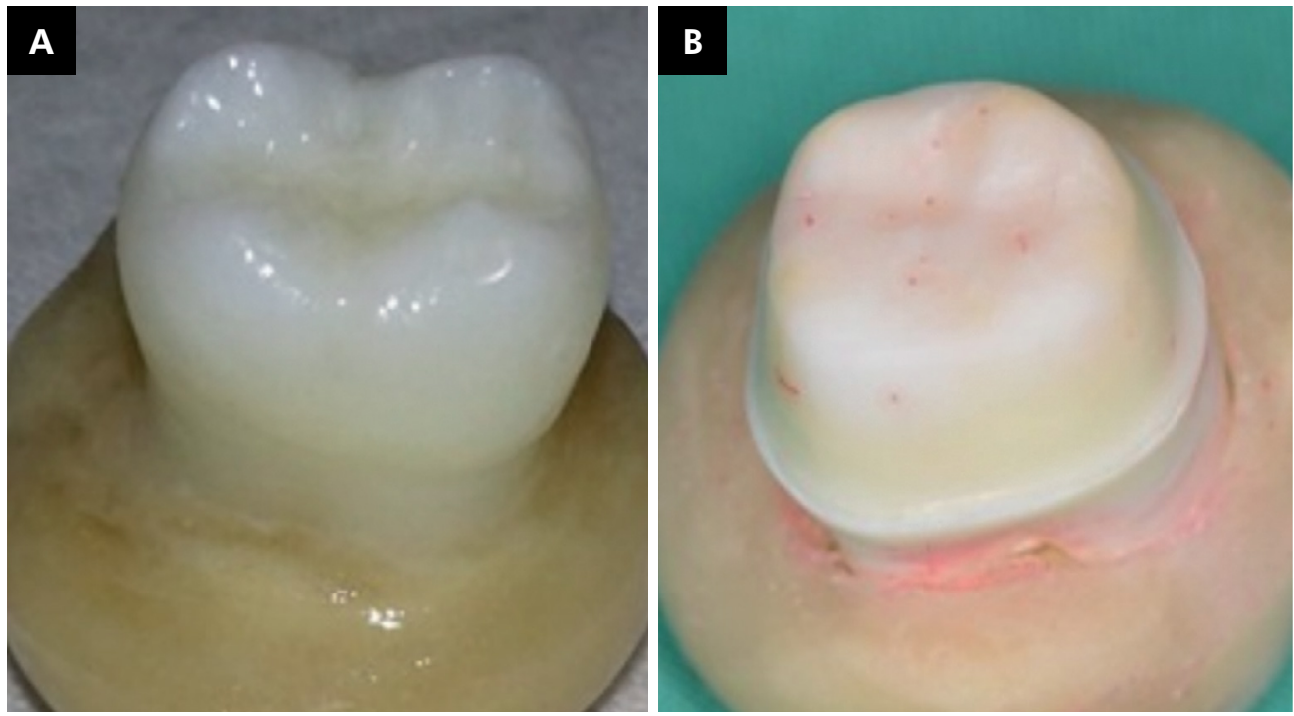

Figure 1. Extracted tooth in the acrylic base before and after preparation.

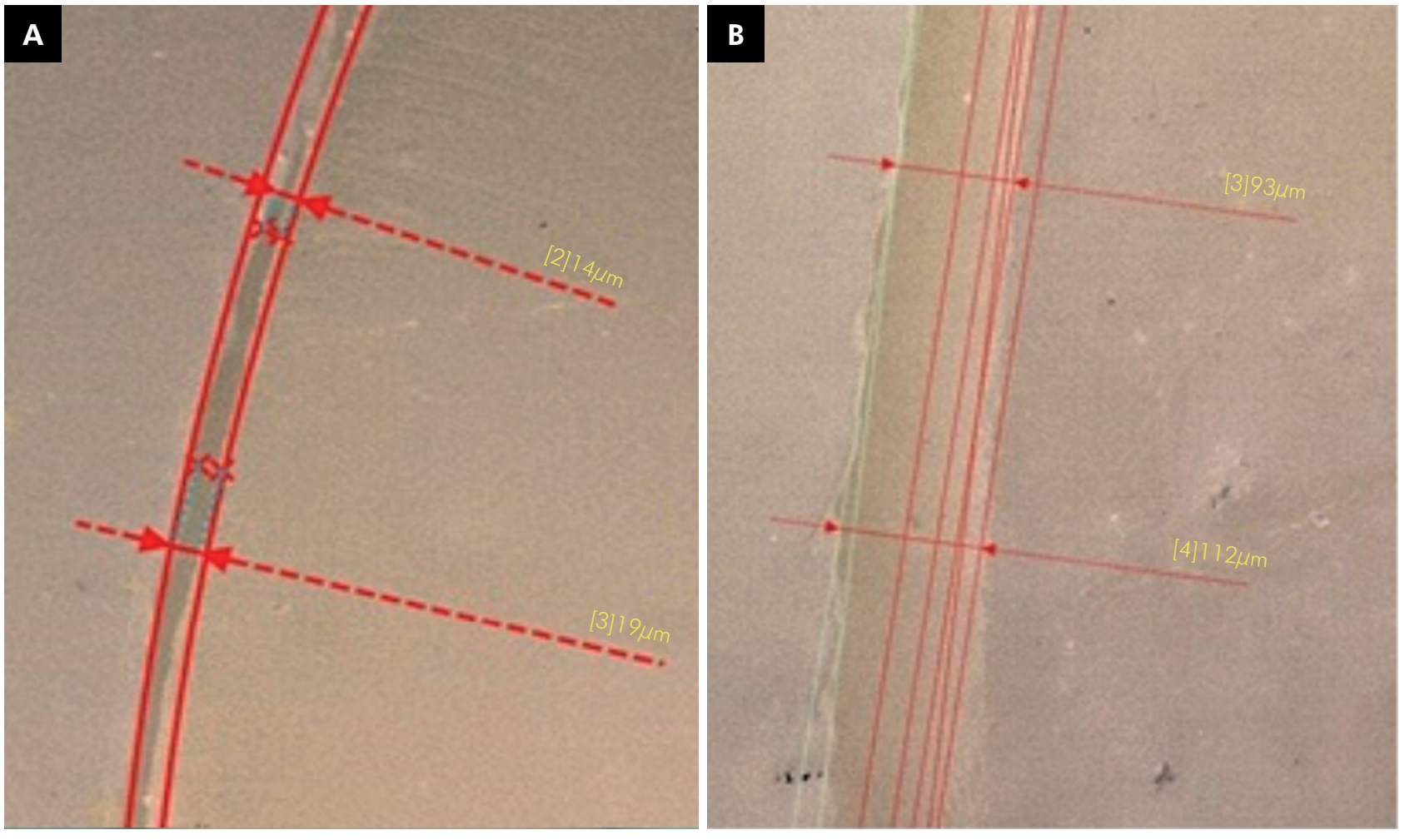

Figure 2. Example of the measurements done on a lithium disilicate pressed and CAD/CAM crown.

\section{Results}

The Shapiro-Wilk normality test failed to demonstrate normal distribution. Therefore, the comparison of the 2 methods was performed by non-parametric Wilcoxon test. This test demonstrated that lithium disilicate pressed crowns had significantly lower values of marginal gaps compared to CAD/CAM crowns $(\mathrm{p}=0.006)$. The mean marginal gap of lithium disilicate pressed crowns was $(38 \pm 12 \mu \mathrm{m})$, while 
the mean marginal gap of e.max CAD crowns was $(45 \pm 12 \mu \mathrm{m})$. Data distribution is shown in a box chart, in which the horizontal line in the box represents the median value (Figure 3). The minimum, maximum, and mean marginal gaps are shown in Table 1 . The Kruskal-Wallis test showed that different teeth had statistically significant differences within each technique (press and CAD/CAM) $(\mathrm{p}<0.0001)$. Box charts show the distribution of values for every tooth in each technique (Figures 4 and 5).

\section{Discussion}

The results of this study demonstrated statistically significant differences between the marginal fit of lithium disilicate CAD/CAM and pressed crowns. The null hypothesis was rejected. The mean marginal gap in the pressed group $(38 \mu \mathrm{m})$ was smaller than in the CAD/CAM group $(45 \mu \mathrm{m})$.

Our results agree with the results of many previous studies, ${ }^{25,26,27}$ which found better marginal fit in pressed lithium disilicate restorations in comparison to lithium disilicate CAD/CAM ones. However, Guess

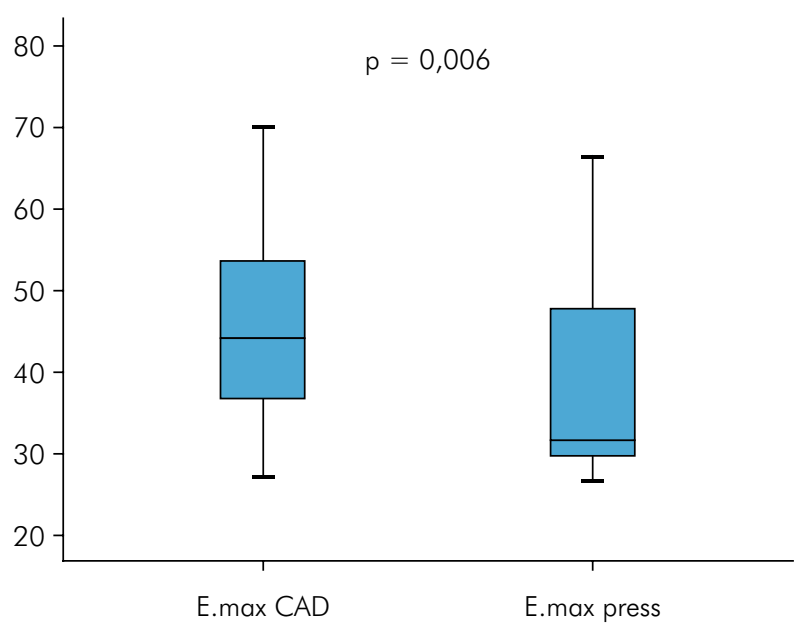

Figure 3. Data distribution. The horizontal line in the boxes represents the median value. et $a l .{ }^{28}$ found no significant difference between the marginal gaps of lithium disilicate CAD/CAM (CEREC 3D InLab) and pressed onlays. Furthermore, $\mathrm{Ng}$ et al. ${ }^{29}$ found better marginal fit in lithium disilicate CAD/CAM (LAVA C.O.S. scanning unit) than pressed

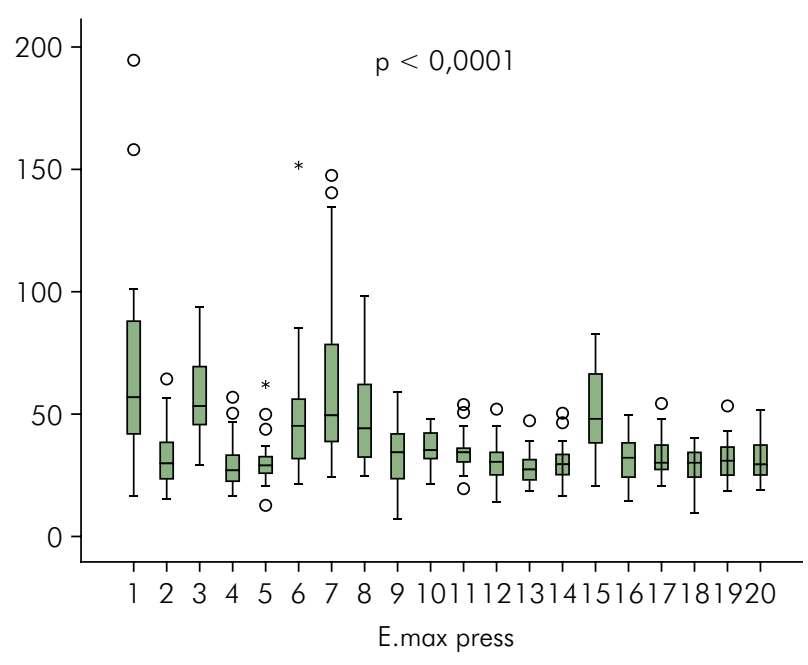

Figure 4. Data distribution for marginal gaps of crowns fabricated with the press technique in each tooth. The horizontal line in the boxes represents the median value in microns.

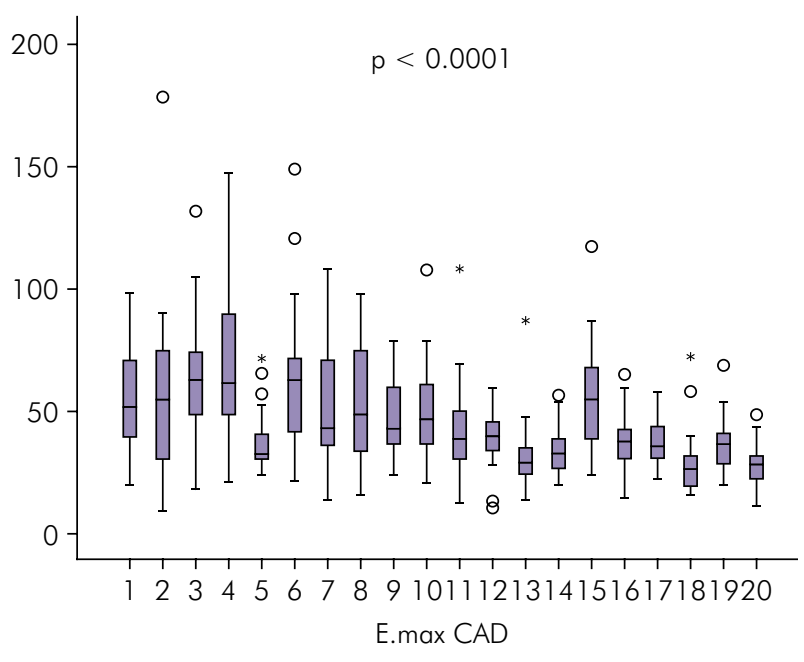

Figure 5. Data distribution for marginal gaps of crowns fabricated with the CAD/CAM technique for each tooth. The horizontal line in the box represents the median value in microns.

Table 1. Minimum, maximum, and mean marginal gaps of e.max press and e.max CAD crowns.

\begin{tabular}{cccccccccccc}
\hline & \multicolumn{3}{c}{ CAD } & \multicolumn{1}{c}{ Press } & \\
Median & Min & Max & Mean & SD & Median & Min & Max & Mean & SD \\
\hline 44 & 27 & 70 & 45 & 12 & 31 & 27 & 66 & 38 & 12 & 0.006 \\
\hline
\end{tabular}


crowns. These discrepancies might be due to the different $\mathrm{CAD} / \mathrm{CAM}$ units, magnifications, and types of microscopes used in each study.

The size of the marginal gaps of crowns fabricated with the two techniques in the current study and in the previously published studies, regardless of the differences found, are still far from perfect when considering the marginal gap in the molecular and bacterial level. Although perfection may not be feasible, ongoing research should be performed in an effort to improve clinical outcomes.

Each technique (press or CAD/CAM) involves a series of steps, and an error could affect the fit of the final restoration. The press method requires transporting the impression to a dental laboratory, subjecting the impression to temperature variations, which has been shown to result in a 1 to $18 \mathrm{~mm}$ dimensional change when temperatures vary from $4^{\circ} \mathrm{C}$ to $40^{\circ} \mathrm{C} .{ }^{30}$ Moreover, the length of time between taking the impression and pouring the stone cast, the ambient temperature, the surface wettability of the gypsum product, and disinfection may cause additional distortions. ${ }^{31,32}$ The application of a die spacer, the fabrication of a wax pattern of the intended crown, and the investment and pressing processes may also induce error. ${ }^{33,34}$ The CAD/CAM technique is subjected to software limitations in the design of restorations and hardware limitations within scanning equipment and the milling machine. Moreover, the expertise of the technician with the CAD/CAM system also affects the outcome of CAD/CAM fabricated restorations. ${ }^{28}$

The marginal gaps were different between the different teeth in each technique (press and CAD/CAM), although the study was conducted on the same types of teeth (intact lower third molars), and using the same preparation protocol performed by a single investigator. Moreover, a single technician fabricated all the crowns using the same protocol according to the manufacturer instructions (Ivoclar Vivadent AG). The differences found in this study can then be explained by a less-than-optimal standardization. In other words, the teeth in this study were prepared by an individual (not a machine), and the extracted lower third molars had different shapes, therefore achieving exactly the same preparation on all teeth was impossible. Thus, the final shape of the preparations could differ between different teeth, which might influence the fit of crowns.

The results of this study are limited by some methodological aspects. The study used only lithium disilicate crowns. Thus, the results cannot be applied to other types of restorations or other restorative materials. The study compared the press technique to a specific $\mathrm{CAD} / \mathrm{CAM}$ technique, which makes the results inapplicable to other CAD/CAM techniques. Despite the drawbacks, this study has some positive aspects, providing important information to the field. The sample size was sufficiently large to avoid type II errors, giving reliability to the results reported. The study was conducted on extracted human teeth, allowing the experiment to be as similar as possible to the intraoral environment. The marginal gap was measured at 25 locations of each restoration, minimizing measurement error, allowing the circumferential fit of the restoration to be estimated with the highest accuracy.

This research provides information about the dimensions of vertical marginal gaps that can be achieved under experimental conditions in vitro with lithium disilicate crowns. However, these in vitro measurements not necessarily reflect the clinical environment, as in vitro studies may differ considerably from everyday clinical practice. The existence of soft tissues and saliva in an intraoral tooth preparation and impression makes the procedures more complicated than in vitro operations. Other related factors might also influence the outcomes, giving the results a low external validity. Despite these limitations, the information reported provides researchers with an important starting point to guide hypotheses for future clinical research. Further studies are required in two separate domains: (1) the consequences of such marginal gaps on the longevity of restorations; and (2) the variations of marginal gaps across different restorative materials.

\section{Conclusion}

Based on this study, which assessed the marginal gaps of lithium disilicate crowns fabricated using a 
press method or a CAD/CAM method, the following observations were made:

1. The press technique demonstrated a significantly smaller marginal gap than the CAD/CAM technique;

2. Both techniques allowed the fabrication of crowns that are within the accepted clinical recommendations for marginal gaps.

\section{References}

1. Hamza TA, Ezzat HA, El-Hossary MM, Katamish HA, Shokry $T E$, Rosenstiel SF. Accuracy of ceramic restorations made with two CAD/CAM systems. J Prosthet Dent. 2013 Feb;109(2):83-7. https://doi.org/10.1016/S0022-3913(13)60020-7

2. Renne W, McGill ST, Forshee KV, DeFee MR, Mennito AS. Predicting marginal fit of CAD/CAM crowns based on the presence or absence of common preparation errors. J Prosthet Dent. 2012 Nov; 108(5):310-5. https://doi.org/10.1016/S0022-3913(12)60183-8

3. Borba M, Cesar PF, Griggs JA, Della Bona Á. Adaptation of all-ceramic fixed partial dentures. Dent Mater. 2011 Nov; 27(11):1119-26. https://doi.org/10.1016/i.dental.2011.08.004

4. Tysowsky GW. The science behind lithium disilicate: a metal-free alternative. Dent Today. 2009 Mar;28(3):112-3.

5. Schaefer O, Watts DC, Sigusch BW, Kuepper H, Guentsch A. Marginal and internal fit of pressed lithium disilicate partial crowns in vitro: a three-dimensional analysis of accuracy and reproducibility. Dent Mater. 2012 Mar;28(3):320-6. https://doi.org/10.1016/j.dental.2011.12.008

6. Subasi G, Ozturk N, Inan O, Bozogullari N. Evaluation of marginal fit of two all-ceramic copings with two finish lines. Eur J Dent. 2012 Apr;6(2):163-8.

7. Glick M, Williams DM, Kleinman DV, Vujicic M, Watt RG, Weyant RJ. A new definition for oral health developed by the FDI World Dental Federation opens the door to a universal definition of oral health. J Am Dent Assoc. 2016 Dec;147(12):915-7. https://doi.org/10.1016/i.adaj.2016.10.001

8. Larson TD. The clinical significance of marginal fit. Northwest Dent. 2012 Jan-Feb;91(1):22-9.

9. The glossary of prosthodontic terms. J Prosthet Dent. 2005 Jul;94(1):10-92. https://doi.org/10.1016/i.prosdent.2005.03.013

10. Holmes JR, Bayne SC, Holland GA, Sulik WD. Considerations in measurement of marginal fit. J Prosthet Dent. 1989 Oct; 62(4):405-8. https://doi.org/10.1016/0022-3913(89)90170-4

11. Hamilton IR, Buckley ND. Adaptation by Streptococcus mutans to acid tolerance. Oral Microbiol Immunol. 1991 Apr;6(2):65-71. https://doi.org/10.1111/j.1399-302X.1991.tb00453.x

\section{Acknowledgement}

We thank the Palacky University for the financial support of this study from grants: IGA_LF_2015_019 and IGA_PrF_2017_011.

We also thank Mgr. Katerina Langova at the department of biophysics - Faculty of Medicine, Palacky University for her efforts in the statistical analysis of this paper.

12. McLean JW, von Fraunhofer JA. The estimation of cement film thickness by an in vivo technique. Br Dent J. 1971 Aug;131(3):107-11. https://doi.org/10.1038/sj.bdj.4802708

13. Björn AL, Björn H, Grkovic B. Marginal fit of restorations and its relation to periodontal bone level. II. Crowns. Odontol Revy. 1970;21(3):337-46.

14. Clarke JK. On the bacterial factor in the ætiology of dental caries. Br J Exp Pathol. 1924;5(3):141-7.

15. Baig MR, Tan KB, Nicholls JI. Evaluation of the marginal fit of a zirconia ceramic computer-aided machined (CAM) crown system. J Prosthet Dent. 2010 Oct;104(4):216-27. https://doi.org/10.1016/S0022-3913(10)60128-X

16. Pak HS, Han JS, Lee JB, Kim SH, Yang JH. Influence of porcelain veneering on the marginal fit of Digident and Lava CAD/CAM zirconia ceramic crowns. J Adv Prosthodont. 2010 Jun;2(2):33-8. https://doi.org/10.4047/jap.2010.2.2.33

17. Jacobs MS, Windeler AS. An investigation of dental luting cement solubility as a function of the marginal gap. J Prosthet Dent. 1991 Mar;65(3):436-42. https://doi.org/10.1016/0022-3913(91)90239-S

18. Kokubo Y, Ohkubo C, Tsumita M, Miyashita A, Vult von Steyern P, Fukushima S. Clinical marginal and internal gaps of Procera AllCeram crowns. J Oral Rehabil. 2005 Jul;32(7):526-30. https://doi.org/10.1111/j.1365-2842.2005.01458.x

19. Boening KW, Wolf BH, Schmidt AE, Kästner K, Walter MH. Clinical fit of Procera AllCeram crowns. J Prosthet Dent. 2000 Oct;84(4):419-24. https://doi.org/10.1067/mpr.2000.109125

20. May KB, Russell MM, Razzoog ME, Lang BR. Precision of fit: the Procera AllCeram crown. J Prosthet Dent. 1998 Oct;80(4):394-404. https://doi.org/10.1016/S00223913(98)70002-2

21. Nakamura T, Nonaka M, Maruyama T. In vitro fitting accuracy of copy-milled alumina cores and all-ceramic crowns. Int J Prosthodont. 2000 May-Jun;13(3):189-93.

22. Lee KB, Park CW, Kim KH, Kwon TY. Marginal and internal fit of all-ceramic crowns fabricated with two different CAD/CAM systems. Dent Mater J. 2008 May;27(3):422-6. https://doi.org/10.4012/dmi.27.422 
23. Wettstein F, Sailer I, Roos M, Hämmerle CH. Clinical study of the internal gaps of zirconia and metal frameworks for fixed partial dentures. Eur J Oral Sci. 2008 Jun;116(3):272-9. https://doi.org/10.1111/j.1600-0722.2008.00527.x

24. Reich S, Wichmann M, Nkenke E, Proeschel P.

Clinical fit of all-ceramic three-unit fixed partial dentures, generated with three different CAD/CAM systems. Eur J Oral Sci. 2005 Apr;113(2):174-9. https://doi.org/10.1111/j.1600-0722.2004.00197.x

25. Mously HA, Finkelman M, Zandparsa R, Hirayama H. Marginal and internal adaptation of ceramic crown restorations fabricated with CAD/CAM technology and the heat-press technique. J Prosthet Dent. 2014 Aug;112(2):249-56. https://doi.org/10.1016/j.prosdent.2014.03.017

26. Neves FD, Prado CJ, Prudente MS, Carneiro TA, Zancopé K, Davi LR et al. Micro-computed tomography evaluation of marginal fit of lithium disilicate crowns fabricated by using chairside CAD/CAM systems or the heat-pressing technique. J Prosthet Dent. 2014 Nov;112(5):1134-40. https://doi.org/10.1016/i.prosdent.2014.04.028

27. Anadioti E, Aquilino SA, Gratton DG, Holloway JA, Denry I, Thomas GW et al. 3D and 2D marginal fit of pressed and CAD/CAM lithium disilicate crowns made from digital and conventional impressions. J Prosthodont. 2014 Dec;23(8):610-7. https://doi.org/10.1111/jopr.12180

28. Guess PC, Vagkopoulou T, Zhang Y, Wolkewitz M, Strub JR. Marginal and internal fit of heat pressed versus CAD/CAM fabricated all-ceramic onlays after exposure to thermo-mechanical fatigue. J Dent. 2014 Feb;42(2):199-209. https://doi.org/10.1016/i.jdent.2013.10.002

29. Ng J, Ruse D, Wyatt C. A comparison of the marginal fit of crowns fabricated with digital and conventional methods. J Prosthet Dent. 2014 Sep;112(3):555-60. https://doi.org/10.1016/i.prosdent.2013.12.002

30. Corso M, Abanomy A, Di Canzio J, Zurakowski D, Morgano SM. The effect of temperature changes on the dimensional stability of polyvinyl siloxane and polyether impression materials. J Prosthet Dent. 1998 Jun;79(6):626-31. https://doi.org/10.1016/S0022-3913(98)70068-X

31. Rodriguez JM, Bartlett DW. The dimensional stability of impression materials and its effect on in vitro tooth wear studies. Dent Mater. 2011 Mar;27(3):253-8. https://doi.org/10.1016/j.dental.2010.10.010

32. Thongthammachat S, Moore BK, Barco MT 2nd, Hovijitra S, Brown DT, Andres CJ. Dimensional accuracy of dental casts: influence of tray material, impression material, and time. J Prosthodont. 2002 Jun;11(2):98-108. https://doi.org/10.1053/jopr.2002.125192

33. Campagni WV, Preston JD, Reisbick MH. Measurement of paint-on die spacers used for casting relief. J Prosthet Dent. 1982 Jun;47(6):606-11. https://doi.org/10.1016/0022-3913(82)90132-9

34. Gorman CM, McDevitt WE, Hill RG. Comparison of two heat-pressed all-ceramic dental materials. Dent Mater. 2000 Nov; 16(6):389-95. https://doi.org/10.1016/S0109-5641(00)00031-2 